\section{ESPACIOS Y VIAJES EN LA VIDA Y EN LA OBRA DE CARMEN DE BURGOS COLOMBINE}

\author{
Concepción Núñez Rey \\ Departamento de Filología Española III \\ Facultad de Ciencias de la Información \\ Universidad Complutense de Madrid \\ Avda. Complutense, $s / n$ \\ 28040, Madrid \\ cnunezre@ccinf.ucm.es
}

\section{SPACES AND TRAVELS IN CARMEN DE BURGOS' LIFE PATHWAY}

\begin{abstract}
Carmen de Burgos (1867-1932) symbolized at her time the efforts to support the progress and the modern ideas; the ideas that the Regenerationism trend had encouraged in Spain. From her very arrival to Madrid in 1901 from her Almeria home town, she started a literary and journalistic career punctuated by so many successes. She signed as Colombine, and became the first female editor of a journal (Diario Universal, 1903), and then the first Spanish War correspondent (Heraldo de Madrid, 1909). She accumulated a large and rich culture made of erudition and was an indefatigable and experienced world-traveller from the European limits to the American furthest corners. Both the spaces and the travels have been given a special importance in her narrative work. Her legacy is made of nearly two hundred titles -among these short and long novels, essays, biographies, travel books, literary studies, translations, prologues, books of interviews along with thousands of articles published by the Spanish and the foreign press- it is a largest literary and scholarly work: a polygraph's work. She was both a minded and an action woman that launched so many press campaigns in favour of social and political causes, especially in favour of women. In our literary story, Carmen de Burgos is the writer who covers the tendencies during the first third of the $20^{\text {th }}$ century, from the Generation of 98 to the innovative currents, our silver age.
\end{abstract}

KEY WORDS: Carmen de Burgos; Colombine; journalism; literature; fiction; Regenerationism; feminism; travels.

\section{UNA VIDA VIAJERA}

El progreso verdadero de los pueblos está en la ética. Lo importante es sentir la vida.

Carmen de Burgos

Dibujar la trayectoria vital y literaria de Carmen de Burgos nos lleva por un largo viaje a través de los espacios que recorrió durante su vida, dejando testimonio de ellos e irguiendo su conciencia, como diría Aleixandre, frente a las
RESUMEN: Carmen de Burgos (1867-1932) simbolizó en su tiempo el afán de progreso y de modernidad que alentó en España la corriente del Regeneracionismo. Desde su llegada a Madrid en 1901, procedente de su Almería natal, emprendió una carrera literaria y periodística jalonada de éxitos. Firmando como Colombine, se convirtió en la primera mujer redactora de un periódico (Diario Universal, 1903), y más tarde en nuestra primera corresponsal de guerra (Heraldo de Madrid, 1909). Acumuló una vasta y rica cultura, hecha de erudición y de experiencia del mundo, por el que viajó incansablemente, de los confines de Europa a los de América. En su obra narrativa, según veremos, encierran especial significado los espacios y los viajes. Su legado lo forma una extensisima labor literaria y erudita, cercana a los dos centenares de títulos: novelas largas y cortas, ensayos, biografías, libros de viajes, estudios literarios, traducciones, prólogos, libros de entrevistas..., junto a miles de artículos publicados en la prensa española y extranjera; la labor de una polígrafa. Fue mujer de pensamiento y de acción, que emprendió numerosas campañas periodisticas en favor de diversas causas sociales o políticas, sobre todo, en favor de la mujer. En nuestra historia literaria, Carmen de Burgos es la escritora que recorre las tendencias del primer tercio del siglo XX, de la Generación del 98 a las Vanguardias, nuestra Edad de Plata.

PALABRAS CLAVE: Carmen de Burgos; Colombine; periodismo; literatura; narrativa; regeneracionismo; feminismo; viajes.

realidades descubiertas. En su contemplación, la autora superpuso muchas miradas: descriptiva, analítica, sentimental, ética, comprometida, estética. También rompió muchos límites en ese peregrinar, con una acción pionera en muchos aspectos, los mismos que hoy se aceptan como parte del funcionamiento normal de una sociedad avanzada.

Había nacido en $1867^{1}$, pero su trayectoria literaria y periodística ocupa el primer tercio del siglo XX hasta su muerte repentina en octubre de 1932, un tiempo que coincide exactamente con la llamada Edad de Plata de la litera- 
tura española, y un tiempo de florecimiento de nuestra cultura en todos los órdenes. Carmen de Burgos ocupó un lugar muy destacado siguiendo de cerca las tendencias dominantes, desde la Generación del 98, de la que sería figura femenina, pasando por el Novecentismo, con el que mantuvo sólidos vínculos, hasta conectar con las estéticas de las Vanguardias, lo que fue propiciado sin duda por la proximidad de Ramón Gómez de la Serna.

En su recorrido, la autora creó una vasta obra, casi inabarcable, con más de un centenar de novelas cortas y largas, ensayos, estudios literarios, biografías, libros de viajes, decenas de traducciones, manuales de uso práctico, y aún hay que añadir miles de artículos en la prensa española y extranjera. Una labor de polígrafa.

\section{El primer viaje. De la provincia a la capital}

El primer gran viaje de Carmen de Burgos la trasladó en 1901 de su Almería natal a Madrid; aunque no fue largo en el espacio, su significado lo convierte en un recorrido inmenso, el más esperado, un viaje trascendental. Había transcurrido la mitad de su vida, en la que, recordemos brevemente, sufrió el infierno de un matrimonio infeliz y la pérdida de tres hijos a poco de nacer. Sobrevivió una hija, que procuró mantener siempre a su lado.

En ese largo tiempo fraguó su carácter decidido y tenaz frente a los obstáculos y, claro está, fue el tiempo de su formación intelectual, autodidacta siempre, aunque logró obtener un título de Maestra de Enseñanza Superior (1898) y una cátedra en la Escuela Normal de Maestras de Guadalajara (1901), que la aproximó a Madrid. Había alcanzado la independencia económica y la libertad para construir su destino. En su bagaje guardaba algo más, el aprendizaje de la profesión periodística en la revista almeriense que dirigía su marido², y la publicación de sus primeros escritos: poemas (coplas populares), cuentos, junto a su primer ensayo sobre un tema esencial en su obra posterior, $L a$ educación de la mujer ${ }^{3}$.

Aún traía como herencia de su pasado algo muy importante para su tarea literaria, la experiencia del paraiso, el recuerdo de un espacio de su niñez, en el que, según ella misma: "corrieron los años más hermosos de mi existencia".
Así aludía al cortijo del valle de Rodalquilar, en el corazón del Cabo de Gata, donde la familia residia durante largas temporadas. La huella de aquel espacio fue tan honda que lo convirtió a través de los años en tema de un gran ciclo novelesco.

Aunque no se instaló en Madrid hasta el otoño de 1901, hay testimonios de su presencia anterior en la capital. Recordemos que figura como socia del Ateneo desde abril de 1895, la tercera mujer después de Emilia Pardo Bazán y Blanca de los Ríos, quienes ingresaron en los dos meses anteriores. Más tarde, desde 1900 su firma aparecía ya en algunos diarios madrileños, como Madrid Cómico o España Artística, y se fue haciendo más asidua en El Globo durante 1902.

En ese breve periodo inicial, en que aparecia con sus dos apellidos, como Carmen de Burgos Seguí, firmó un artículo de especial significado, que nos obliga a detenernos. Lo tituló "Larra y Espronceda"4 $y$, aunque lo publicó con meses de retraso, en él describía su visita a las tumbas de los dos escritores en el viejo cementerio de San Nicolás el 1 de noviembre de 1901. Era su primer homenaje a Larra de los muchos que vendrán después, aunque este fuera compartido:

me llevaba un sentimiento de admiración hacia dos grandes hombres, que representaban dos grandes infortunios [...] en mi memoria se agitaban las hermosas poesías de Espronceda, tan amargas y vehementes como tiernas y bellas, la correcta y castiza prosa de Larra, su critica fría, acerada, mordaz y abrumadora. [...] Esos seres cuya sensibilidad llega a hacerse dolorosa, porque les hieren amarguras desconocidas para la generalidad, que [...] necesitan poseer una abnegación sin límites para vivir dedicados a sus semejantes, o se destrozan en la lucha, se aniquilan y mueren como Espronceda, o rompen su cárcel valientemente como Larra.

Con su solitario e íntimo homenaje, Carmen vertía su propio dolor frente a la realidad, compartido con el maestro, al que elegía así como modelo para su incipiente carrera de escritora. Ignoraba aún que esa misma acción la habian realizado meses antes, en forma pública, un grupo de escritores que la historia iba a consagrar como Generación del 98. No será el único factor que la vincule al grupo, al que incluso por edad debería pertenecer, y con el que 
compartió sobre todo la preocupación por España y el compromiso con su regeneración.

Muy pronto llegó un gran acontecimiento: el 1 de enero de 1903, Carmen de Burgos inauguró su columna diaria "Lecturas para la mujer" en el naciente Diario Universal5. Desde ese día nació Colombine, el seudónimo que la hizo popular y la acompañó siempre. Colombine, en francés, más sofisticado que Colombina, como reflejo de la influencia modernista triunfante en aquellos años ${ }^{6}$. Según palabras de la autora, fue Augusto Suárez de Figueroa, el director del periódico, quien le propuso tal nombre, y años después reflexionaba así sobre el significado que había tenido en su vida.

¡Colombine! Acepté el pseudónimo porque me lo dio un periodista insigne, un maestro, y quise revestirme al escribir de alegres carcajadas, de ligera frivolidad, de loco cascabeleo y relumbrón de lentejuelas de metal y collares de vidrio, de todo el aturdidor torbellino en que aparece envuelta la romántica, graciosa y picaresca hija de Casandra, esa creación de la comedia italiana que conquistó el mundo con sus risas [...] Se logra pocas veces; la escritora que sueña, piensa y analiza no puede reír con la alegre despreocupación de la pagana Colombine. Debía una reparación a esa deliciosa criatura, desvirtuada por mí.

Con plena conciencia ve nuestra autora la función que cumple a su lado ese seudónimo, la de un modelo desdramatizador, tan alejado de su personalidad y de la práctica de su vida, que le venía a servir de catarsis, o de escudo protector ante la incomprensión que suscitaba su labor.

Carmen de Burgos se convirtió por tanto en la primera redactora de un periódico, es decir, en la primera periodista profesional de España.

En ocasiones declarará el ferviente amor por su profesión de periodista, evocando el trabajo desarrollado lentamente durante años, adherido al discurrir de la vida cotidiana, de modo que se superpone y confunde con ella:

yo [...] que me he sentido periodista tan fervorosamente, [...] lo que ha sido más constante en mí, lo que ha sido el almanaque entrañable y asiduo de mi vida; lo que, aunque no me sobreviva, me ha hecho vivir; lo que es la unidad profesional de mi vida: tienen todos estos trabajos adherida la anécdota del día siguiente a su publicación; esa anécdota que alarga y apasiona su vida 8 .

Ese amor al periodismo perduró siempre en Carmen. Otra contundente afirmación de su profesión se contiene en su entrevista con el Caballero Audaz, cuando declara que espera resucitar: "por hacer alguna información periodística que se les escape a los futuros reporteros y que exija inaplazablemente la actualidad. ¡Porque yo soy tan periodista como novelista!"9.

En un principio, le propusieron que tratara en su columna los temas convencionalmente femeninos, pero muy pronto rompió esos límites para ocuparse de temas que afectaban a toda la sociedad: el trabajo, la educación, la infancia, la situación de las cárceles, la pena de muerte.

En cuanto a la mujer, utilizó su columna desde el comienzo para intentar cambiar, con paciencia pero con determinación, su situación social discriminatoria. Carmen de Burgos no sólo tenía formación e información para afrontar la empresa, también había sufrido en sí misma largos años de clausura e indefensión, que habían alimentado lentamente su lúcido análisis de la realidad y su voluntad de actuar, guiada siempre por el afán de mejorar las condiciones de vida de los seres y de alcanzar leyes más justas y humanas, un pensamiento racionalizador que participaba de la ancha corriente del Regeneracionismo español.

Alimentaba su afán modernizador en los modelos que procedian de Europa, tomados de los libros, y también de los periódicos, donde buscaba toda noticia que significara progreso. Por otras vías, explicaba la situación de dependencia asignada a las mujeres en los códigos, lo que la mayoría de ellas desconocía: "intolerable que la madre no tenga dentro de la familia los mismos derechos del padre, y que la mujer casada no tenga el de administrar libremente sus bienes y el pleno uso de los derechos civiles, considerándola siempre como una menor sometida a la tutela del marido" (Diario Universal, 9-V-1904). La vía fundamental fue la defensa de la necesidad de su educación como base de un progreso que afectaría, no sólo a la mujer, sino a la sociedad entera: "soy partidaria de instruir a la mujer y proporcionarle medios de trabajar, como único modo de dignificarla, haciéndola independiente y capaz de atender por sí sola a sus necesidades" (29-VIII-1903).

ARBOR CLXXXVI EXTRA JUNIO 2010 5-19 ISSN: 0210-1963 
A fines de 1903, su labor precursora dio un paso decisivo. Desde el periódico, convocó una encuesta para debatir la necesidad de una ley de divorcio. Las respuestas de escritores y políticos a quienes Carmen solicitó directamente su opinión aparecieron en la columna paralela "El pleito del divorcio". Todas ellas conservan hoy un gran valor histórico por la importancia de los nombres que las firmaban (Unamuno, Giner de los Ríos, Maura, Canalejas...), y como descripción del ambiente ideológico de comienzos de siglo. La consulta obtuvo un gran éxito: "De nuestro plebiscito resulta que la opinión en España es favorable al divorcio, y es indudable que se establecerá entre nosotros como conquista de la civilización"10. Junto a la popularidad que le proporcionó esta campaña, la autora se atrajo la repulsa y la persecución de los sectores más conservadores, que no sólo hubo de sufrir durante toda su vida, sino que perduraron sobre su memoria tras la Guerra Civil.

Por estas acciones primeras será contemplada con el tiempo como pionera del feminismo español o, como dirá alguno de sus exégetas muchos años después:

Divorcio, voto femenino, igualdad de los hijos ante la ley... Estas nuevas realidades españolas, ¿cómo dieron sus primeros pasos entre nosotros? [...] ¿Quién lanzó las semillas generosas que al fin, tras la hostilidad y el hielo de muchos años, llegan hoy a puerto de triunfo? [...]. Ser ahora abanderado de los derechos de la mujer, cuando ya están conseguidos o a punto de conseguirse no es peligroso ni meritorio. Meritorio y peligroso lo era antes, en 1905, en 1910, aun en 1915, cuando una voz orientada en ese sentido sólo despertaba un eco casi unánime de protesta. Carmen de Burgos [...] fue periodisticamente la iniciadora, la precursora de estas realidades ya incorporadas a la Constitución. No hubo campaña periodística sobre estos temas que ella no hiciera, adelantándose en el tiempo a la modalidad más reciente -reportaje, encuesta- del periodismo nuestro"11.

En sus artículos, Carmen de Burgos no desplegaba argumentos convencionales o afirmaciones abstractas. Se documentaba, reflexionaba y argumentaba buscando llevar al lector una idea irrefutable por el sentido común, al margen de dogmas, combinada a veces con impresiones subjetivas o sentimientos. La finalidad es siempre educar y buscar la justicia.
Con intención divulgadora, persigue un estilo ágil, conciso y claro; del mismo modo, utiliza cuidada y medidamente un léxico semiculto, es decir, accesible, pero a veces salpicado de expresiones que enriquezcan al lector. Los artículos de Carmen tienen casi siempre dos lecturas: la finalidad práctica que persiguen, y el anhelo intelectual que subyace en ellos. Por último, hay que subrayar la superioridad de la autora a la hora de la denuncia o de la sátira, sobre todo cuando analiza críticamente un fenómeno social. Destaca siempre en ella la coherencia de criterios, la lucidez del análisis y la nitidez de la expresión. Son las claves de la labor periodística de la autora, incluidos los temas principales que trató, y todo ello conformó el éxito alcanzado.

Aún hay algo más en aquellas fechas; para comprender lo que Carmen de Burgos había logrado en menos de tres años, recordemos la despedida que Heraldo de Madrid le dedicó en su portada el 5 de octubre de 1905, al tiempo que anunciaba su colaboración con el diario, a cuya redacción perteneció ya para siempre:

"la nombradía de la que goza, y que ha hecho popular en periódicos y revistas el pseudónimo de Colombine [...] después de lúcidas campañas en la prensa española, emprende ahora un viaje por el extranjero [...] tendrán conocimiento los lectores del Heraldo por los artículos con que nos honrará la notable escritora que en el expreso de anoche salió para París. Carmen de Burgos es ante todo y sobre todo uno de los elementos más valiosos del periodismo español" (Jueves, 5-X-1905).

\section{Hacia la Europa anHELAda}

Llegamos al segundo gran viaje, el que Carmen de Burgos emprendió en otoño de 1905 para recorrer ciudades de Francia e Italia a lo largo de un año. Europa había sido su constante referencia, pero de forma libresca. Ahora, por fin, iba a descubrir Europa con sus propios ojos, y llevaba preparada una mirada abierta de par en par, que depositaba en sus crónicas enviadas a Heraldo de Madrid y a $A B C$, y que más ampliamente reelaboró a su regreso en su primer libro de viajes, Por Europa ${ }^{12}$.

El momento fue de nuevo decisivo. Daba inicio a su incesante viajar durante más de un cuarto de siglo, y sus 
columnas pasaron a ser una ventana por la que España se asomaba a Europa, atenta siempre a toda idea que pudiera representar una influencia benéfica para nuestro país. A veces comparando, como en Suiza: "ese pueblo ha hecho su ideal de la educación y cultura de sus hijos; no perdona sacrificio para robustecerlos y tener ciudadanos fuertes de cuerpo y espíritu. Se envían al extranjero en busca de los vivificantes aires del mar todos los niños que lo necesitan; se llevan otros a los sanatorios de las montañas; se les cuida y se les instruye... ¡Pobres niños españoles! Con cuánta pena los comparo con estos..." (p. 448). A veces criticando: "¿Estaremos muertos para el entusiasmo más noble y grande que puede sentirse? No quiero admitirlo... pero ¿qué se ha hecho aquí por nuestros hombres geniales? ¿Dónde halla el viajero sus recuerdos? ¿Dónde se les honra? ¿Acaso no tenemos nombres dignos de figurar entre los primeros del mundo?" (p. 68). Y muchas lamentando el atraso de España: "Cuanto más veo los decantados adelantos del extranjero, más pena siento por España. Nosotros tenemos una savia potente, una primera materia sana y pura para ser grandes" (p. 334). Pero su actitud es siempre fruto del amor: "siempre late el corazón bajo el cielo de la patria, sobre todo si es tan hermosa y desdichada como España" (p. 496).

Una obra de arte, un palacio, el mundo técnico, un paisaje o la vida de la gente son registrados con exactitud, a veces se incluyen datos, cifras, referencias documentales, pero todo se tiñe siempre de una manera de ver que nos da sobre todo una impresión de vida, real e intensa.

Durante su recorrido, entró en contacto con organizaciones como el Lyceum Club y creó un entramado de relaciones con periodistas, escritores y artistas, convertido en verdaderos vínculos de amistad con figuras como Alfredo Naquet, Max Nordau, Matilde Serao o Roberto Bracco.

Entre todas las ciudades visitadas, París y Nápoles iban a ser los lugares amados a los que había de regresar, pero fue en Roma donde se produjo la apoteosis de su viaje. Invitada por la Asociación de la Prensa italiana, el 28 de abril pronunció la conferencia "La mujer en España", en cuyo texto encontramos un estudio exhaustivo de su situación en aquella época, y un documento de gran valor histórico. Su pensamiento era guiado tanto por la conciencia del atraso como por la esperanza de progreso: "Toda la tarea consiste en saber dirigir y aprovechar nuestras fuerzas. No somos un pueblo decrépito; somos más bien un pueblo infantil, a propósito para llegar a una juventud potente"13.

Al final del viaje, la mirada de la autora se ha envuelto en un halo cosmopolita. Los largos meses en contacto con una sociedad culta, refinada y liberal ofrecieron a sus ojos un modelo de vida luminosa, opuesto a la rigidez y la oscura intolerancia que dominaban en el espíritu social español. En adelante, su incesante viajar será expresión de ese deseo insatisfecho de libertad, que la llevará con los años a las largas estancias fuera de España. Por ahora, medita así, mientras regresa, sobre el propósito de su labor:

Dentro de pocos dias estaré de nuevo en Madrid; ahí me espera el trabajo, la constante lucha... la eterna rebeldía que levanta mi pensamiento contra el terrible fardo de prejuicios, convencionalismos y miserias que nos oprimen.

Luchar contra esa montaña, resquebrajarla, abrir en ella surcos para que germinen la Justicia y la Libertad, es un empeño semejante al que hizo salir a D. Quijote a los campos de Montiel. Lo sé. Sé que las fuerzas de una mujer no removerán la montaña, pero acaso le arranque un grano de arena y enseñe a otros el camino... La lucha es la vida y yo siento el ansia de vivir"14.

De inmediato, entre los granos de arena, fundó en su casa una tertulia literaria (los "miércoles de Colombine"), emulando los salones visitados en París o Roma, abiertos por damas ilustradas. Y en ese mismo otoño de 1906, Carmen promovió su primera campaña en pro del voto femenino, una nueva labor pionera. Pretendía repetir la experiencia del plebiscito, como la emprendida tres años antes en torno al divorcio, dirigiéndose de nuevo a las figuras políticas e intelectuales más conocidas. El 19 de octubre abrió en Heraldo de Madrid la columna "El voto de la mujer" anunciando la publicación de diversas opiniones. Se cerró el 25 de noviembre, esta vez, con un rotundo fracaso. Muchas opiniones contrarias procedian de los sectores progresistas, que por primera vez manifestaban su temor a la posible tendencia conservadora del voto femenino. El mismo temor que protagonizó el debate del otoño de 1931, en los comienzos de la Segunda República. Junto a los resultados, publicaba un análisis muy meditado de la actitud predominante en España acerca de los derechos de la mujer:

"el pueblo español, comparado con el de otras naciones, sufre un notable atraso; es aún mayor el peso de los atavismos

ARBOR CLXXXVI EXTRA JUNIO 2010 5-19 ISSN: 0210-1963 
que la fuerza del progreso que lo impulsa. La mujer necesita en España conquistar primero su cultura; luego, sus derechos civiles, puesto que en nuestros Códigos no la conceptúan en muchos casos persona jurídica, y después hacer que las costumbres le concedan mayor libertad, más respeto y condiciones de vida independiente. Entonces estará capacitada para conquistar el derecho político" (25-XI-1906).

Destacaba, no obstante, la posición excepcional de España en el ámbito europeo y la necesidad futura de atender esta demanda: "La Alianza internacional para el sufragio de las mujeres cuenta ya con Comités en todas las naciones, menos en España, Portugal y Austria". Infatigable, siguió divulgando las acciones de las sufragistas en el escenario europeo.

Siguieron años de intensa labor literaria. La tertulia de Carmen se convirtió en un foco cultural de la vida madrileña por el que pasaban figuras consagradas y jóvenes promesas: de Galdós a Salvador Rueda o a Rubén Darío, de Tomás Morales a Juan Ramón Jiménez o a Ramón Gómez de la Serna.

Pero Ramón llegó en 1908 para quedarse, y con ello transformó la vida de la autora. Un año después iniciaron una relación sentimental que rompió muchas convenciones y los iba a mantener unidos durante veinte años. Al encontrarse, Carmen era ya una escritora consagrada que acumulaba una extensa labor y era requerida para innumerables proyectos. Desde 1907, la autora aparece como figura destacada entre los escritores que integraron la "promoción de El Cuento Semanal", aquella colección de novelas cortas, fundada por Eduardo Zamacois, modelo de otras muchas que vinieron después, alcanzando grandes tiradas y una difusión de la literatura sin precedentes. Carmen participó de principio a fin como una de las plumas más asiduas, lo que en gran medida la especializó en este modelo narrativo. Casualmente, su muerte, en 1932, coincide con el fin de La Novela de Hoy, última colección importante de aquel movimiento editorial.

Con la recopilación de relatos Cuentos de "Colombine"15 había alcanzado el reconocimiento de la crítica literaria, que consolidó un año después con la publicación de Los inadaptados ${ }^{16}$, su primera novela larga. Con ella conformó el universo mítico del valle de Rodalquilar, ya esbozado en relatos breves anteriores, y dio comienzo al largo ciclo narrativo que en torno a ese espacio cultivó de forma intermitente.

Años muy intensos, en los que Carmen fundó además Revista Crítica, casi al tiempo que Ramón fundaba Prometeo (más duradera gracias al apoyo paterno), colaborando uno y otro en ambas publicaciones. Sus páginas son testimonio del gozoso comienzo de su relación, en especial, el "Ágape" organizado en Fornos en 1909, que ambos presidieron para celebrar el centenario de Larra.

En paralelo, se fraguaba el primer proyecto erudito de Carmen de Burgos, el estudio de la vida y la obra del gran poeta romántico Leopardi ${ }^{17}$, mal conocido en España, cuya obra había descubierto durante su estancia en Nápoles. Solicitó la traducción de la obra lírica a jóvenes poetas amigos, cuyos nombres figuraban al pie de cada poema; entre la larga nómina, colaboraba Juan Ramón Jiménez.

Aún hubo más en el prodigioso 1909; en agosto, tras los sucesos del Barranco del Lobo, la autora llegó a Melilla para informarse del magno desastre y enviar sus crónicas a Heraldo de Madrid. A su regreso, venciendo dificultades, y superada la censura militar, firmó uno de sus más ardientes alegatos antibelicistas en el artículo "¡Guerra a la guerra!": "No existe ninguna barbarie comparable a la que suscita la guerra, y sin embargo, se les concede tanto poder a los que las sostienen, que la prensa enmudece, los ciudadanos callan, y todos la secundan, escudados en la frase absurda de que es un mal necesario. ¡Necesaria la guerra!"18.

Avanzaba de nuevo por su destino de pionera; con su labor en Melilla se convirtió en la primera mujer española corresponsal de guerra.

\section{NuEVAS MIRADAS VIAJERAS}

A partir de 1910 se da en la autora una progresiva intelectualización de su compromiso social, y reflexiona con frecuencia en obras y artículos sobre la necesidad del racionalismo para la vida y para la literatura, una propuesta como vehículo de futuro, no como mirada atrás:

El racionalismo que ahora os asusta, fue la felicidad de nuestra Grecia, de la Itaca del arte [...]. El estar de cara al pasado 
os perjudica. Mirad al porvenir, a la luz. Sacudid la herencia de muertos que os aplasta con su fardo de historia y de siglos [...] es preciso que dejéis el puesto a los vástagos nuevos que traigan la idea redentora [...]. El racionalismo ${ }^{19}$.

Este proceso evolutivo, consolidado en adelante, la aproxima a la corriente literaria que ha de triunfar en España en la segunda década del siglo: el Novecentismo. Con algunos de sus miembros sostuvo además la autora estrecha amistad (sobre todo con Juan Ramón Jiménez y con Gregorio Marañón), y junto a ellos la sitúa, por ejemplo, Eugenio G. de Nora ${ }^{20}$, incluyéndola entre los novelistas intelectuales.

Testimonio de esta nueva mirada de la autora nos lo da el viaje que emprendió en el verano de 1911 por Bélgica, Holanda y Luxemburgo, más tarde depositado en Cartas sin destinatario, su segundo gran libro de viajes. Lo que sus ojos han visto es sometido a reflexión, en un esfuerzo de estilización y distanciamiento. En su primer libro, aparecía volcada sobre la realidad exterior, registrándolo todo, ahora su mirada está dividida entre esa realidad y la de su mundo interior, con plena conciencia: "La vida es tan subjetiva, que todo lo que no está en nosotros no está fuera de nosotros" 21 . Con frecuencia alude a su ansia de conocer, al anhelo insatisfecho, a la fugacidad de toda vivencia: "Cada casita del camino, cada tren en marcha, cada vapor que navega en alta mar llevan con ellos mi deseo. No sé ir a un sitio sin decirme: 'Volveré'. Me apena la idea de que el árbol que miro no ha de fijar más mi pupila" (p. 183).

Inundan las páginas las reflexiones estéticas; no sólo el análisis de las obras de arte, sino su personal concepción artística: "En toda manifestación pictórica me interesan sobre todo los primitivos. Tienen para mí una seducción, un encanto, una ingenuidad que no llegan a superar nunca los maestros que les siguen" (pp. 43-44).

En un verdadero periplo triunfal, registrado puntualmente en la prensa, se convirtió el viaje de Carmen para impartir conferencias en Argentina, entre el verano y el otoño de 1913. De su viaje interior resultó la novela La travesía ${ }^{22}$; de su reflexión sobre el país visitado resultó el ensayo Impresiones de Argentina ${ }^{23}$. Lo leyó en un acto ante sus paisanos, que la recibieron en forma clamorosa cuando el barco en que regresaba atracó a finales de octubre en el puerto de Almería. Con igual clamor había sido recibida poco antes durante su escala en Canarias. En cuanto a las conferencias que pronunció en Buenos Aires y en La Plata, la prensa española daba noticia de su éxito, y la argentina registraba las sucesivas intervenciones, en las que habló de pintura española, ilustrándolo con "proyecciones luminosas". No sólo evocó a los grandes maestros, sino que presentó a figuras modernas como Sorolla o Zuloaga y, con mayor atención, a Romero de Torres. También registraban los diarios, con abundantes imágenes, las recepciones y banquetes con que fue homenajeada.

En 1914 emprendió la autora un viaje que iba a tener una trascendencia inesperada. Recorriendo sin premura varios países europeos, se proponía llegar a Noruega, hasta Cabo Norte. Heraldo de Madrid publicaba las crónicas viajeras, que dos años más tarde se reunirán y completarán en Peregrinaciones ${ }^{24}$. Será su último gran libro de viajes, el más complejo e integrador de diversas miradas, salpicado incluso de una muy novedosa mirada vanguardista, y también, un magnífico documento social del estallido de la Gran Guerra.

Al inicio, ya en Suiza comenzó a sentir una impresión de bienestar (la palabra que después ha definido el modelo social europeo) y, después de un recorrido evocador siguiendo el curso del Rhin, atravesó hasta Hamburgo, donde admiró el poderío comercial y el asombroso progreso técnico, que ya incluía máquinas para diversos servicios: "Es la ciudad de los automáticos para todo, no se pierde el tiempo. Se toman en automáticos sellos, billetes de tranvías, de ferrocarril, suplementos; se cambian monedas. La mayoría de los restaurantes son automáticos [...] En las tiendas hay automáticos que ofrecen la fruta, el pan y los diferentes artículos sin molestar al vendedor" (Heraldo de Madrid, 9-VIII-1914).

Al llegar a los países escandinavos descubrió la sociedad soñada casi hecha realidad, y estudió con detenimiento su modelo de bienestar, más avanzado aún en Noruega, donde encontró libertad y tolerancia, respeto de todos, ausencia de maldad, costumbres sanas en contacto con la naturaleza, gusto por el deporte, y muy especialmente, respeto escrupuloso hacia la mujer, preservando su libertad individual y su integración social en todos los ámbitos, incluso en la administración, donde gozaba ya de todos los derechos legales.

ARBOR CLXXXVI EXTRA JUNIO 2010 5-19 ISSN: 0210-1963

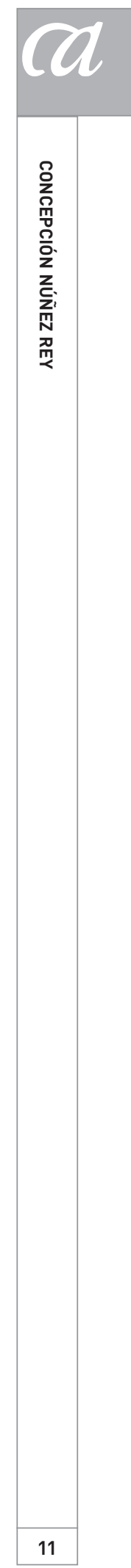


De regreso, los paises se habían transfigurado y hubo de atravesar el infierno. La guerra la obligó a renunciar al proyectado retorno a través de Rusia. La barbarie de la guerra no sólo destruía el bienestar, también disolvía todo valor en las relaciones humanas. Presenció deportaciones masivas, linchamientos, y ella misma corrió peligro de ser fusilada cuando la confundieron con una espía rusa. Sufrió penosas situaciones hasta llegar en barco a Inglaterra y regresar a España, casi sin equipaje, a finales de agosto. Heraldo y La Esfera reflejan de cerca el resurgir en la autora de sus ideas antibelicistas, que en innumerables artículos se irán desgranando hasta el final del conflicto en 1919: unas veces, con imágenes conmovedoras ("Las violetas de Verdún"), otras veces, aterradoras ("Los hombres tronco"). Y sin cesar, dará cuenta de los progresos sociales que, paradójicamente, la guerra traerá para las mujeres.

\section{Portugal, como un nUevo paraíso}

Desde su primera visita en el verano de 1915, el afán viajero de Carmen encontró sosiego en Portugal. Sobre todo Lisboa y el estuario del Tajo sintetizaban para ella muchas cosas buscadas: su paisaje y su clima placenteros, e íntimamente, la acogida fraternal de escritores, artistas y políticos de cuyo afecto disfrutó en adelante. El país llegaría a convertirse en su segunda patria: "Es preciso ver Portugal para completar el paisaje total de nuestra península; para completar el alma nacional hay que atender a esta visión tan armónica y tan complementaria, que nos hace amar la península entera de una manera más fundamental y amplia, en un cuadro más perfecto" 25 .

Recordemos que Carmen contagió después a Ramón Gómez de la Serna su admiración por Portugal, y que fue allí donde ambos vivieron con mayor libertad, sin miedo a la maledicencia, su ya larga relación amorosa: "Mi sensación era que había huido y vivía la eterna juventud de los amantes a los que nadie pregunta nada y los reciben en los gabinetes más honestos del mundo"26.

Los medios lisboetas conocian bien la figura de Carmen de Burgos cuando llegó a la ciudad en agosto de 1915. Su fama y su prestigio habían traspasado las fronteras españolas hacía tiempo, convertida en símbolo del pensamiento progresista femenino. "Colombine está en Lisboa" fue la acogida que $A$ Capital le dio en su portada (23-VIII-1915) con una larga entrevista y una semblanza de su figura. En ella aparecía ya dándole la bienvenida Ana de Castro Osório, quien se iba a convertir para siempre en su más grande amiga, con quien compartir un largo proyecto común. Ana de Castro era una de las figuras más respetadas e influyentes de la naciente República portuguesa, que tenía tras de sí un largo recorrido en la política, la literatura y el periodismo, y una meta esencial, la defensa de los derechos de la mujer, unida a la protección de la infancia. Fue ella quien abrió a Carmen las puertas de las más altas instituciones de la República, y quien convirtió a sus grandes figuras en amables anfitriones de nuestra autora. La acompañó en las entrevistas a los presidentes Teófilo Braga ${ }^{27}$ y Bernardino Machado ${ }^{28}$, 0 a otros personajes ilustres como Magalhâes Lima, y promovió diversos actos en su homenaje, en especial, una gran fiesta en barco, recorriendo el estuario al atardecer, anunciada y descrita con gran espacio en la prensa lisboeta ("Un precioso vaporcito nos esperaba al pie de la escalinata de mármol de la Plaza del Comercio"29, recuerda la autora). Desde su regreso a Madrid, Carmen comenzó a publicar en Heraldo de Madrid este primer documento del pais, sus artículos "De Portugal".

En el momento de su encuentro con Carmen, Ana de Castro desarrollaba el proyecto de una nueva organización que agrupase a las mujeres al servicio de la República y que ocupase el vacío dejado por los hombres a causa de la guerra; en paralelo, debía prestar ayuda a las viudas y a los huérfanos causados por el conflicto. Nació así en 1916 la Cruzada das Mulheres Portuguesas, una organización que iba a tener singular trascendencia, no sólo para el feminismo portugués, sino también para el español a través de Carmen de Burgos, quien llegará a fundar la Cruzada de Mujeres Españolas.

Desde 1916 se sucedieron las visitas de Carmen y Ramón al país, donde descubrieron rincones entrañables y secretos, o disfrutaron gratas veladas en el salón familiar de Ana de Castro. De los primeros viajes a Portugal nos dejó la autora muchos datos concretos en el amplísimo capítulo que incluyó en Peregrinaciones. Pasados unos años, llegará a escribir la muy autobiográfica novela La Flor de la Playa ${ }^{30}$, recreando la intensa experiencia de aquel verano y de otros sucesivos en que, junto a Ramón, disfrutó de un rincón apartado y sosegado para poder escribir, Praia das Maçãs: "es una playa encantadora, que no se ha contaminado aún 
de la vulgaridad de las otras playas". El otro refugio llegó más tarde, en 1922, cuando los dos autores emprendieron el proyecto de hacerse un hotelito junto a la gran explanada de Estoril, que se convirtió en un verdadero palacete rodeado de pinos, Ilamado El Ventanal.

Nuestra autora ambientó en Portugal casi una decena de sus novelas, muchas de ellas, las más experimentales y vanguardistas. Recordemos, por ejemplo, El hastío del $a^{a m o r}{ }^{31}$, donde a modo de collage insertaba la traducción de las famosas cartas de amor de la monja Mariana Alcoforado, o el experimento descriptivo de El suicida asesina$d o^{32}$. En conjunto, Carmen nos ofrece un vivo retrato del Portugal de comienzos del siglo XX, que se completa con más de un centenar de artículos aparecidos en la prensa española, no sólo en Heraldo, en los que divulgó el arte, las costumbres y la historia portuguesas: la historia y la intrahistoria del pais.

Mención aparte merece la difusión de su literatura, emprendida por la autora en 1920 a través de la revista Cosmópolis, que dirigía Enrique Gómez Carrillo. En sus páginas abrió la sección "Crónica literaria de Portugal", donde reunió rigurosa información y textos representativos para ofrecernos una novedosa panorámica de los modernos autores portugueses.

Desde 1919 se estrecharon los vínculos entre Carmen y Portugal. La fiel amiga de la República Portuguesa va a ser recompensada con grandes honores por diferentes estamentos. El Gobierno condecoraba en un decreto del 12 de agosto: "com o Grau de Comendador da Ordem de S. Tiago da Espada, a escritora e jornalista espanhola Dona Carmen de Burgos". Asimismo, desde aquel verano fue invitada a colaborar con el diario 0 Mundo para realizar una labor inversa, la de difundir en Portugal aspectos políticos y culturales de la vida española: "Amiga dedicada de Portugal, tendo-nos prestado relevantes serviços, a brilhante redactora do Heraldo de Madrid é uma mulher de letras na mais alta significação desto termo, considerada em toda a parte onde tem feito brilhar os seus dotes intelectuais. E'com o maximo regosijo que anunciamos a colaboração assidua de Colombine" (18-X-1919). Su columna "Coisas de Espanha. Crónica de Colombine", que inauguró el 19 de octubre, reunió durante más de dos años un contenido misceláneo sobre temas políticos y culturales sometidos a reflexión crítica, prestando especial atención a los problemas que podian afectar a ambos paises.

Y hemos de recordar que, en aquel año, la autora vio elevarse su prestigio como estudiosa y erudita con la publicación de Figaro, la gran biografía de Larra considerada canónica hasta hoy, con la que culminaba su largo homenaje al maestro. Por desgracia, acabada su labor, se manifestó por primera vez la grave enfermedad cardiaca que padecía.

Sus largas estancias en Portugal se iniciaron en enero de 1920, cuando Carmen fue invitada por el gobierno portugués para impartir un curso de Literatura Española en la Universidad de Lisboa. Durante el mes de mayo se produjo otro gran acontecimiento, el ciclo de conferencias que pronunció en el "Salão Nobre da Academia de Sciencias", en la que ingresó como miembro honorífico. Al tiempo recibió el homenaje de la Cruzada das Mulheres Portuguesas, en un acto en que era proclamada "socia benemérita".

\section{La Cruzada de Mujeres Españolas, LA LIGA INTERNACIONAL Y LAS NUEVAS TRAVESÍAS HASTA AMÉRICA}

Ya en Madrid, Carmen fundó a su vez la Cruzada de Mujeres Españolas con la participación de figuras destacadas: la doctora Concepción Aleixandre, presidenta de la Unión de Mujeres de España; la marquesa del Ter, presidenta del Consejo Nacional de Mujeres, Magdalena Santiago Fuentes, Josefa Barrera, Carmen Blanco y otras muchas. Los proyectos de la asociación, presidida por la autora, eran "influir en la legislación y trabajar en pro del mejoramiento social de la mujer" (Heraldo, 2-VIII-1920). Tal meta hacía necesaria la participación política. La Cruzada serviría para la ayuda práctica a la mujer y para la propaganda feminista; el partido Unión Republicana, que aceptaba sus propuestas, para la acción política y la influencia en las leyes, y el Consejo Nacional de Mujeres, fundado el año anterior, insertaba el feminismo español en la Alianza Mundial.

Antes de un año, el 30 de mayo de 1921, la Cruzada encabezó una acción pionera, la primera manifestación sufragista en la calle, que acabó ante el Congreso para hacer entrega de todas sus reivindicaciones. Con Carmen 
a la cabeza, repartieron un manifiesto de nueve puntos en que condensaban sus aspiraciones de igualdad legal y protección para la mujer. Es el momento de recordar aquella encuesta de 1906 sobre el voto femenino que Carmen promovió desde Heraldo de Madrid, y de recordar su tenacidad de tantos años frente a una sociedad hostil a la participación cívica de la mujer.

Poco después, las dos Cruzadas se integraron en un proyecto más ambicioso, la Liga Internacional de Mujeres Ibéricas e Hispanoamericanas, impulsada en 1922 desde Nueva York por la mexicana Elena Arizmendi, quien ofreció la presidencia a Carmen de Burgos como figura emblemática en todos los ámbitos feministas de la cultura hispana. El proyecto era reunir la fuerza dispersa de figuras y organizaciones feministas de todos los países Iberoamericanos. En las páginas de Revista de la Raza se abrió la sección "Feminismo Internacional" desde el otoño de 1924, convirtiéndose así en el órgano de difusión de la Liga.

Paralela a la acción, discurría la vida intelectual de la autora, que en mayo de 1922 era invitada como conferenciante en las tribunas de la Sorbona y del Museo del Louvre; y discurría su intensa actividad literaria, favorecida por las largas estancias en Estoril junto a Ramón. Pero sobre aquel dorado retiro pesaba una hipoteca que los obligó a venderlo en abril de 1926. Se consolaron en Nápoles, donde residieron durante varios meses, que dieron como fruto la novela de Carmen El "Misericordia"33, y diversos artículos sobre la historia, la cultura y la vida napolitana.

Poco antes, en 1925, Carmen visitó México y Cuba para impartir conferencias sobre literatura y sobre feminismo en Universidades y centros cívicos. Su enfermedad la obligó a suspender los actos que iba a celebrar en Nueva York. Dos años después, emprendió la última travesía, que la llevó por el canal de Panamá hasta Perú, Bolivia y Chile, donde tuvo recibimientos muy calurosos, incluso por parte de los gobernantes. De nuevo, novelas y artículos recogieron el testimonio de su último gran viaje ${ }^{34}$. La descripción física de las ciudades la salpicaba con evocaciones históricas, datos científicos, observaciones sociales e impresiones subjetivas, pero no recoge los actos que ella misma protagonizó y que tuvieron tanta resonancia en la prensa de cada país. En el gran diario de Chile El Mercurio y en su revista Zig Zag, donde Carmen colaboraba desde comienzos de los años veinte, encontramos todos los eventos que protago- nizó durante su estancia en el país: sus conferencias, los homenajes, las visitas, incluso a la isla de Juan Fernández, siguiendo el reclamo del Robinson literario.

Antes de partir hacia América en octubre de 1927 dio a la imprenta La mujer moderna y sus derechos ${ }^{35}$. Los sucesivos estudios de Carmen en torno al problema femenino son ahora reelaborados y ofrecidos desde los más diversos puntos de vista, remontándose incluso hasta los mitos primitivos. Una obra enciclopédica y un documento de valor esencial para el conocimiento de la evolución social de la mujer.

\section{La llegada de la República y el Último viaje de Carmen de Burgos}

No es fácil resumir el inmenso esfuerzo que emprendió Carmen de Burgos en 1931, al comienzo de la Segunda República Española; llegaba el momento esperado, pero su salud era ya muy frágil. Un año antes, ingresó en el Partido Republicano Radical Socialista y reactivó la propaganda de la Cruzada y de la Liga, con lo que regresaron los grandes temas sociales que defendió en incesantes campañas: el divorcio, la pena de muerte, el voto femenino, la condena de la prostitución. Participó en actos resonantes, como el celebrado en Almería para homenajear a Salmerón, donde figuraba junto a Unamuno, Victoria Kent e Indalecio Prieto. Meses antes de morir, ella misma era objeto de homenaje al convertirse en miembro de la Sociedad Económica Matritense de Amigos del País, en la que ingresó con un discurso sobre "Actuación y acción de las mujeres en las Sociedades Económicas". Alcanzaba así el reconocimiento a su larga labor regeneracionista y a su estirpe ilustrada.

Prosiguió en aquellos días su tarea literaria con la biografía del general Riego ${ }^{36}$ y con su novela larga Quiero vivir mi vida ${ }^{37}$, prologada por Gregorio Marañón. Se añadieron varias novelas cortas, entre las que destaca Puñal de claveles $^{38}$, como canto a la libertad y testamento final.

Su vida se detuvo el 9 de octubre de 1932. En el plano real, al atardecer del día 8 sobrevino el colapso de su corazón cuando intervenía en un acto cultural del Partido Republicano Radical Socialista, desde cuyas filas se iba a presentar a diputada en las siguientes elecciones. Su repentina pérdi- 
da provocó honda impresión y su entierro en el Cementerio civil de Madrid se convirtió en un duelo masivo. La prensa nacional e internacional se hizo eco durante varios dias y se dedicaron homenajes a su memoria ${ }^{39}$.

En un plano simbólico podemos utilizar una imagen muy querida por ella. Un cuadro del pintor simbolista Böcklin (se conservan varias versiones), que admiró en Basilea en 1914 y que utilizó para cerrar su biografía de Riego (1931). Se titula "La isla de los muertos", pero ella lo llamó "La isla del reposo", y hacia esa isla se dirigió Carmen en la madrugada del 9 de octubre, después de su fecunda vida.

Ramón, que la conoció de verdad, había dicho de ella algo sencillo y hermoso: "Sus ojos, que parecen ver, no hacen más que pensar". Y así la había representado Romero de Torres, leyendo y parándose a meditar.

\section{Los espacios en los relatos de Carmen de Burgos ${ }^{40}$}

Si el recorrido por los espacios tuvo tanta importancia en la vida de Carmen de Burgos, es preciso buscar el reflejo en su labor de escritora. En efecto, vemos que muchas de sus novelas (no sólo los libros ya citados) se enmarcan en viajes, y que casi todas nos sitúan en un lugar definido, por lo que esos espacios cobran gran importancia; es decir, una importancia añadida a la que teóricamente tiene el espacio como elemento estructurador del relato.

Para ordenar los enfoques desde los que tratar el espacio en la narrativa de Carmen, es preciso distinguir primeramente entre espacios reales y literarios. Según Ricardo Gullón: "Entre el espacio literario y el territorial, geográfico, la diferencia es la siguiente: esencia aquél, accidente éste, en cuanto integrante de la novela. Cierta tendencia a confundirlos puede ser alentada por el hecho de ser el uno parte del otro"41.

En las novelas de la autora abundan, desde luego, los espacios reales, observados en sus peculiaridades ("accidentes"), captados como ricos documentos; en sí mismos, el valor de esos espacios en la narración presenta unos límites que el propio Gullón establece: "la identificación del espacio como natural y real inclina a pensar el texto como reportaje" (p. 26). Pero no se mantuvo la autora en esos límites, por supuesto; en la abundancia misma de esos espacios se descubre ya algo más: significados que estaban en el punto de partida, a los que se han venido a sumar otros nuevos, todos ellos de verdadero valor literario.

Parece evidente que de la experiencia vital de un autor depende la visión del mundo que condiciona su obra, o es su obra misma. Según esto, recordemos que, en el punto de partida, Carmen aparece atrapada en un espacio cerrado que limita sus ansias vitales. La larga frustración vivida dejó en ella tal señal que su impulso permanente será la búsqueda de espacios nuevos, soñados siempre como espacios de la libertad. Los desplazamientos personales de la autora repercuten en sus novelas, en las que se reflejan las etapas: de la provincia a la capital; de la capital a otros paises; y de ellos (nueva insatisfacción) al viajar constante, siempre más allá. Este momento crítico es registrado en una novela esencial, El perseguidor ${ }^{42}$. Los dos espacios antagónicos, cuya oposición aparece como clave de la aventura personal y literaria de Carmen, los explica Gullón de un modo que se ajusta perfectamente al caso de la autora: "La clausura sugiere la idea de un orden, mientras la inmensidad incita a buscar en viajes y aventuras la libertad en que aquel se disuelve" (p. 9).

Antes de examinar los espacios literarios de sus novelas, parece necesario atender a los espacios reales en que se enmarcan: los que son fruto de la observación, los que componen el "reportaje", contienen lo accidental, el costumbrismo. El despliegue de espacios representados en la narrativa de la autora y el esfuerzo de exploración del mundo que contienen obligan a ordenar su extensión y composición. De España, es Madrid el marco fundamental en unos veinticinco relatos; Toledo, Aranjuez, Sevilla, Granada, Barcelona, el Monasterio de Piedra, la Ciudad Encantada, Jaca, son los espacios de otros tantos títulos. Pero es entre el Cabo de Gata y Almería, sobre todo en Rodalquilar, donde se sitúan más de una decena de relatos; a veces este espacio no aparece nombrado, o tiene el nombre cambiado, pero sus rasgos son inequívocos, como en $E I$ anhelo. De Europa, Francia es el país favorito, sobre todo Paris, marco total o parcial de casi una decena de obras; $y$ tres más se sitúan en Niza, en la región de Auvernia y en Deauville. Portugal es el otro pais preferido; de sus ciudades ocupan un importante papel en las novelas de Carmen: Lisboa, Coimbra, Sintra, Cascais, Estoril, Beja, Praia das Maças. También son representadas las ciudades de Italia: 
Venecia, Florencia, Roma, Nápoles. De Suiza, Ginebra y Basilea aparecen en los relatos. De Holanda, Amsterdam, Rotterdam, las islas de Zuiderzee. Aún nos sitúan las novelas, aunque parcialmente, en Londres, en Cristianía, en Bergen, en algún lugar alemán. En las novelas de su última etapa nos conduce la autora a América: Buenos Aires, México, Viña del Mar (Chile), Hollywood, Cuba. Aún sitúa un relato en Melilla, otro en pleno océano; y poquísimos quedan sin referencia espacial concreta. Predominan, entre todos ellos, los espacios urbanos sobre los naturales en una proporción de tres a uno.

Siempre reproduce Carmen en sus presentaciones espaciales una toponimia fiel, junto con nombres de calles, de cafés, de hoteles, de teatros, que hoy se revisten de un enorme poder evocador. Su incansable actividad viajera, su mirada para captar lo esencial de cada mundo sin agotar los detalles y su magistral creación de ambientes convierten su obra total en un vasto recorrido por la Europa del primer tercio de siglo.

Hasta aquí, el ancho mundo que la autora nos ofrece; pero veamos cómo lo ofrece. No le interesa el retrato exhaustivo de los espacios; actúa sobre ellos de modo selectivo para componer una imagen condensada, intensa y abarcadora, nunca convencional. Ramón Gómez de la Serna valora la importancia del espacio y del tiempo en la obra literaria para juzgar el modo como Carmen opera con ellos:

Carmen reconoce el espacio y el tiempo de los que tiene una idea viva, espontánea, vidente, hialina, diáfana. Carmen conoce y se da cuenta hasta del cielo [...].

Carmen encuentra el punto mágico y desapercibido, el conmutador disimulado, el llamador, ese algo por el que el lector logra la creación más que el relato de todo lo que ella ha visto. Carmen mira las cosas con esperanza, con ilusión, con pasmo, con ansiedad, con deslumbramiento, con inocencia, con esa gran apetencia que es irreparable no tener ${ }^{43}$.

A ella le interesan las vivencias, intelectuales, emocionales o sensitivas, nacidas en los espacios, por eso en sus obras aparecen espacios vividos, más que subjetivos. Tal vez son así porque, según hemos visto, Carmen busca en ellos algo que está siempre más allá. Se ajustan muy bien a la definición de Michel Butor sobre el espacio vivido: "Todo lugar es el centro de un horizonte de otros lugares, el punto de origen de una serie de recorridos posibles que pasan por otras regiones más o menos determinadas" 44 .

Sobre los espacios observados tiende la autora diferentes miradas: a la mirada objetiva se superpone la de las impresiones subjetivas, la de las emociones personales, la del humor satírico, y también, una mirada ética y una mirada existencial; una mirada, por ello, permanentemente activa y compleja.

Por otra parte, describe los espacios de sus relatos incorporando perspectivas, conversiones y juegos. En descripción panorámica o sucesiva se presenta Madrid en La mujer fría; por sectores o parcelas diferenciadas se describe un espacio de la costa portuguesa en La Flor de la Playa. El espacio concreto de Recoletos es construido tan sólo por una sensación que lo recorre y por el dinamismo de las figuras que lo ocupan, en iTodos menos ese! Como haria un pintor, en El tesoro del castillo se marcan según las distancias los planos del paisaje. Una combinación alternada del espacio de la multitud, del espacio del grupo y del espacio de la conciencia individual se da en Siempre en tierra. Verdadero juego parece el indicar un desplazamiento en el espacio mediante la progresiva distancia de dos sonidos, en Puñal de claveles. De efecto deslumbrante es la manera cinematográfica, por planos, como compone la autora el alejamiento de un barco al iniciar su travesía, recogiendo sólo la percepción subjetiva de las distancias sucesivas (Malos amores). Los ejemplos podrian multiplicarse.

Llegamos por fin a lo que Ricardo Gullón considera, según su distinción, verdadero espacio literario, el que es portador de algún significado que hemos de interpretar. También en este nivel la obra de Carmen desborda en abundancia. Reservando para el final los espacios de significación fundamental, podemos desgranar otros muchos, portadores de una disparidad de significados. Abundan los espacios de encuentro social, útiles para el estudio de grupos y para la sátira: tertulias (El veneno del arte), bailes (Ellas y ellos o ellos y ellas), cafés (Los negociantes de la Puerta del Sol), casinos (El permisionario), barcos (Malos amores). Hay espacios que atrapan al individuo y lo transforman e integran (o convierten), como la Puerta del Sol en Los negociantes..., o en Vida y milagros del pícaro Andresillo Pérez (Gullón los llama "espacios-fuerza"). En "Villa María", el espacio del hotelito de clase media se hace alienador y, por último, aniquilador; en Luna de miel, el espacio inhabitual altera 
y perturba una relación amorosa. Otros son espacios de la degradación, como aquellos en que caen las heroínas de La rampa y de El dorado trópico, o como los ámbitos de actuación profesional en Los usureros.

Gran importancia tienen los espacios cerrados ("del confinamiento", para Gullón), de donde los héroes pugnan siempre por huir: en El honor de la familia, la protagonista huye de un cerco familiar opresor, que se funda en unas creencias sociales; en El fin de la guerra, los personajes se hallan atrapados en un país afectado por la guerra, detrás de lo cual se reproduce la incomunicación y desconfianza que rigen la relación entre los pueblos; en La malcasa$d a$, se suceden los espacios cerrados formando círculos concéntricos: la protagonista es prisionera de un vínculo matrimonial, en torno al cual se tiende el entramado social de una ciudad, y más allá del cual encuentra aún unas leyes sociales consolidadas e inamovibles.

Importante papel juegan también los espacios iniciáticos, en los que el personaje sufre un aprendizaje que modifica su visión del mundo: la enfermera de Pasiones evoluciona en el escenario de un hospital de guerra desde su inicial intención humanitaria hasta la conciencia rebelde de colaborar como una pieza en la maquinaria bélica; espacio iniciático es también la Puerta del Sol para Andrés Pérez, en Vida y milagros..., o para don Justo, en Los negociantes...; y lo es también el que recorre el joven Gaspar Garcilaso en busca de su identidad, para descubrir, como en un círculo, que ésta se hallaba en el punto de partida (El tío de todos).

Algunos espacios sirven a un experimento vital que exige la ruptura con lo cotidiano (La prueba, La Flor de la Playa). Otros son espacios del fingimiento: el de la hipocresía social (Una bomba), el de la estafa (Los anticuarios). Otros son espacios de exploración del misterio, como los escenarios del esoterismo, en El retorno. Hay espacios para la evocación histórica, como Versalles, en Siempre en tierra. Y espacios que encierran un homenaje en clave, como el que rinde la autora a la tertulia "ramoniana" describiendo el café Pombo durante una redada de conspiradores liberales (Don Manolito). Y también el espacio no humano, que se hace literario al hallarle dimensión humana, como el zoológico de Lisboa en Los amores de Faustino.

Asimismo, encontramos en las novelas desde el espacio multitudinario de la masa humana que invade el Bosque de Vin- cennes, en el que se diluye la conciencia individual (Siempre en tierra), hasta el espacio íntimo de la conciencia en que se desarrolla totalmente la narración de El novenario, o de Confidencias. En este punto aparece otra vez la originalidad de El suicida asesinado, en que el espacio de la conciencia intima es alterado obsesivamente, e inundado por otro espacio, el del mar, único del que esa conciencia se hace cargo. Hay, por otro lado, el espacio amado, entrañable, punto de referencia de evocaciones y nostalgias, como ese rústico albergue junto al mar que es La Flor de la Playa, de valor biográfico para la autora, pero también representativo de los que son para otros sus lugares inolvidables y secretos.

Llegamos a los espacios simbólicos, portadores de muy diversas significaciones. Un sentido social tiene el espacio de la piscina por representar una nueva concepción de la vida e introducir costumbres basadas en la libertad y el placer (iLa piscina, la piscina!). En otro extremo, el espacio de las montañas aparece con un sentido trascendente, por la inutilidad de escalarlas intentando ver más allá de ellas: misterio que sería tan insalvable como el del sentido de la vida humana (El novenario).

Como en un círculo, volvemos al significado general que tienen las novelas de Carmen de Burgos, para descubrir que todos sus espacios se funden en dos fundamentales. Rodalquilar, el lugar en que están fijados los orígenes de la autora, se erigió para ella, desde la distancia, en imagen del paraíso perdido (según Gullón, los paraísos son por naturaleza perdidos); alcanzada la dimensión de espacio mítico, Carmen construyó en torno a él un gran ciclo novelesco.

En otra dirección, la autora recorre multitud de espacios cuyas imágenes va depositando en sus novelas y en sus libros de viajes (la diferencia fundamental entre ellos es la presencia o la ausencia de la ficción); pero busca algo más. En todos ellos, Carmen busca uno intuido como espacio de la plenitud. Se multiplica en testimonios su ansia de ubicuidad: "mi espíritu siente ansia de extenderse, de penetrar en todo, de caminar por los caminos desconocidos"45. También por naturaleza, ese espacio de plenitud anhelado es inalcanzable.

Desde la privilegiada posición que ocupaba Ramón junto a Carmen, supo descubrir, y nos descubre: "Todo lo que después ha ido viendo ella por el mundo lo había visto ya en Rodalquilar" ${ }^{46}$. No sólo ha visto lo mismo; ha buscado lo

ARBOR CLXXXVI EXTRA JUNIO 2010 5-19 ISSN: 0210-1963 
mismo. Al final, los dos espacios se unen: el paraíso perdido y la ubicuidad inalcanzable son un único espacio, el del anhelo imposible de plenitud. La búsqueda existencial de la autora se desplegó vital y literariamente en esa doble dimensión espacial.

Desde este prisma, su compromiso social y el esfuerzo de su labor responden al deseo de crear ese paraiso en la realidad.
La literatura de Carmen está al servicio de ese mecanismo de exploración; Por esta razón, viaja por distintos niveles del espacio: por sus tiempos, por su sociedad y por su propia conciencia individual ante ese espacio. Sobre ello tiende además, complicándolo, una mirada multiforme, flexible y abarcadora, que va del compromiso lúcido a la emoción sensible. En sus novelas, como en sus libros de viajes, están también todas las miradas.

\section{NOTAS}

1 Desde 1989 (ver bibliografía), está fijada y documentada por mi, mediante partida de bautismo, la fecha del 10 de diciembre de 1867. A pesar de ello, se sigue publicando en ocasiones una fecha incorrecta, alegando además que es dudosa.

2 Almería Cómica (1883) y Almería Bufa (1886).

3 Reunió todos estos escritos bajo el título Ensayos Literarios, Almería, s.ed., 1900.

4 El Globo, Año XXVIII, 28 de mayo de 1902 (en portada). Tres días antes fueron trasladados los restos de ambos autores y del pintor Rosales desde San Nicolás a la Sacramental de San Justo.

5 En el mismo mes comenzó su colaboración periódica con $A B C$, también naciente.

6 Más adelante, su amigo y admirador José Francés firmará como Pierrot, otro personaje de la Comedia del Arte, su prólogo al libro Cuentos de Colombine (1908).

7 "Colombine y Pierrot", en Al balcón, Valencia, Ed. Sempere, s.a. (1913), p. 96.

8 "Autobiografía", en Al balcón, ob. cit., p. V.

Recibido: 14 de mayo de 2010

Aceptado: 7 de junio de 2010
10 Burgos, C. de (1904): El divorcio en España, Madrid, Vda. de Rodriguez Serra, p. 142.

11 Montero Alonso, José (1931): "Carmen de Burgos ("Colombine") fue la autora de la primera encuesta periodistica en torno al divorcio", Nuevo Mundo, Madrid, n. ${ }^{1963,} 24$ de octubre de 1931.

12 Burgos, C. de (s.a., 1906): Por Europa, Barcelona, Casa Editorial Maucci. Las cuatro citas siguientes, referidas a esta obra, sólo señalarán la página.

13 Burgos, C. de (1906): La mujer en España, Valencia, Ed. Sempere, p. 9.

14 Burgos C. de: Por Europa, ob. cit., pp. 502-3.

15 Burgos C. de (1908): Cuentos de "Colombine", Valencia, Ed. Sempere.

16 Burgos C. de (1909): Los inadaptados, Valencia, Ed. Sempere. Contiene además tres cuentos: Amor de esposa, ¡Veinte años! y En la paz del campo.

17 Burgos C. de (s.a., 1911): Giacomo Leopardi (su vida y sus obras), Valencia, Ed. Sempere, 2 vols.

18 Burgos, C. de: Al balcón, ob. cit., p. 201.

19 En el libro de diálogos La voz de los muertos, Valencia, Ed. Sempere, 1911 (pp. 107 y 114).

20 La novela española contemporánea, tomo II, 2. a edición, Madrid, Ed. Gredos, 1973, p. 41. La misma vinculación establece José Domingo (en La 
novela española del siglo XX, tomo I, Barcelona, Ed. Labor, 1973, pp. 70126. También en "La prosa narrativa hasta 1936", en Historia de la Literatura Española "coordinada por José María Díez Borque", tomo IV, El siglo XX, Madrid, Taurus, 1980, p. 106). La reproducen Granjel y Mainer (en Historia y crítica de la Literatura Española, Tomo VII. Época contemporánea: 1914-1939, Barcelona, Editorial Crítica, 1984, p. 147).

21 Burgos, C. de (s.a., 1912): Cartas sin destinatario, Valencia, Ed. Sempere, 232. La autora comentó la reciente publicación del libro en su columna "Femeninas" de Heraldo de Madrid, el 1 de agosto de 1912. La reseña de Prometeo apareció en su número XXXVIII, perteneciente a la primavera de 1912

22 La travesía, o Malos amores, Madrid, El Libro Popular, Año III, n. ${ }^{\circ} 11,17-$ III-1914.

23 Impresiones de Argentina, Almería, $\mathrm{H}$. Navarro de Vera, MCMXIV.

24 Peregrinaciones, Madrid, Imprenta de "Alrededor del Mundo", 1916. Reeditado como Mis viajes por Europa (otro título de Peregrinaciones), Madrid, Ed. Sanz Calleja, s.a. (1917), 2 vols.

25 Peregrinaciones, ob. cit., pp. 329 y 385.

26 Gómez de la Serna, R. (1974): Automoribundia, Madrid, Ed. Guadarrama, Col. Punto Omega, 2 v., p. 302.

27 Teófilo Fernandes Braga (184312924), profesor, escritor y político.
En 1910 fue Jefe del Gobierno Provisional, y Presidente de la República entre mayo y octubre de 1915. Fue figura principal de la Escuela de Coimbra y autor de una vasta obra poética y erudita.

28 Bernardino Machado Guimarães (1851-1944). Catedrático en la Universidad de Coimbra. Gran Maestre en la masonería entre 1895 y 1899. Ministro en varias ocasiones y Presidente de la República desde octubre de 1915. Dejó también una extensa obra política y literaria.

29 Peregrinaciones, ob. cit., p. 408.

30 La Novela Corta, Madrid, Año V, n. ${ }^{\circ} 231,29$ de mayo de 1920. Aparece reeditada en el volumen La Flor de la Playa y otras novelas cortas, Madrid, Castalia, 1989. Edición de Concepción Núñez Rey.

31 La Novela Corta, Madrid, Año VIII, n. ${ }^{\circ} 410,13$ de octubre de 1923. Con ilustraciones de Bradley.

32 La Novela Corta, Madrid, Año VII, n. ${ }^{\circ} 339,3-\mathrm{VI}-1922$.

33 La Novela Mundial, Madrid, Año II, n. ${ }^{\circ}$ 73, 4-VIII-1927.

34 La misionera de Teotihuacán, Madrid, La Novela Mundial, Año I, n. ${ }^{\circ}$ 21, 5-VIII-1926. El dorado trópico, Madrid, La Novela de Hoy, Año IX, n. ${ }^{\circ} 404,7-I I-1930$.

35 Valencia, El Adelantado de Segovia, 1927.

36 Gloriosa vida y desdichada muerte de D. Rafael del Riego, Madrid, Biblioteca Nueva, 1931.
37 Madrid, Biblioteca Nueva, 1931. Con "Prólogo" de Gregorio Marañón.

38 Madrid, La Novela de Hoy, Año XI n. ${ }^{\circ} 495,12-\mathrm{XI}-1931$.

39 Desde Lisboa, Ana de Castro escribía conmovida: "Carmen de Burgos, a grande escritora espanhola [...] é um valor mundial que tôdas as mulheres devem respeitar, embora mesmo não concordem com a suas crenças e não estejam à altura do seu pensamento desanuviado e liberto de quaisquer dogmas e preconceitos sociais".

40 Las etapas y los temas predominantes de su narrativa, junto a un estudio detenido de personajes y lenguajes se pueden ver en Núñez Rey, C. (2006): "La narrativa de Carmen de Burgos, Colombine. El universo humano y los lenguajes", Arbor (CSIC), Madrid, n. ${ }^{0}$ 719, pp. 347-361.

41 Gullón, R. (1980): Espacio y novela Barcelona, Antoni Bosch, edit., p. 8.

42 La Novela Corta, Madrid, Año II, n. ${ }^{\circ} 59,17-\| 1-1917$.

43 G. de la Serna, R. (1916): "Epílogo" a Peregrinaciones, de Carmen de Burgos, ob. cit., pp. 440 y 430.

44 Butor, M. (1967): Sobre literatura, II, Barcelona, Seix Barral (Biblioteca Breve), p. 59.

45 Cartas sin destinatario, ob. cit. p. 16.

46 G. de la Serna, R.: "Prólogo" a Confidencias de artistas, Madrid, Soc. Española de Librería, S.A. (1916), p. 14 